\title{
Preoperative chemotherapy in colorectal cancer patients with synchronous liver metastasis
}

\author{
NOBUKI ICHIKAWA ${ }^{1}$, TOSHIYA KAMIYAMA ${ }^{1}$, HIDEKI YOKOO ${ }^{1}$, \\ SHIGENORI HOMMA ${ }^{1}$, YOSHIAKI MAEDA ${ }^{2}$, TOSHIKI SHINOHARA ${ }^{2}$, YOSUKE TSURUGA $^{3}$, \\ KEIZO KAZUI $^{3}$, HIROAKI IIJIMA ${ }^{4}$, TADASHI YOSHIDA ${ }^{1}$ and AKINOBU TAKETOMI ${ }^{1}$ \\ ${ }^{1}$ Department of Gastroenterological Surgery I, Graduate School of Medicine, Hokkaido University, Sapporo, \\ Hokkaido 060-8638; ${ }^{2}$ Department of Gastroenterological Surgery, Hokkaido Cancer Center, Sapporo, Hokkaido 003-0804; \\ ${ }^{3}$ Department of Surgery, Hokkaido Hospital, Japan Community Healthcare Organization, Sapporo, Hokkaido 062-8618; \\ ${ }^{4}$ Clinical Research and Medical Innovation Center, Hokkaido University Hospital, Sapporo, Hokkaido 060-8648, Japan
}

Received May 23, 2019; Accepted November 13, 2019

DOI: $10.3892 / \operatorname{mco} .2020 .1992$

\begin{abstract}
The response to preoperative chemotherapy is useful for predicting prognosis in unresectable and resectable disease. However, the prognostic benefit of chemotherapy prior to hepatectomy in patients with colorectal carcinoma and resectable or marginally resectable liver metastases remains unclear. The present study investigated the effect of preoperative chemotherapy on the prognosis of patients with colorectal cancer and resectable or marginally resectable synchronous liver metastasis. A total of 106 patients were retrospectively reviewed, who underwent hepatectomy for colorectal metastasis. The prognosis of 64 patients who received neoadjuvant chemotherapy (NAC) were compared with the 42 patients who did not (non-NAC). Furthermore, a total of 43 patients who responded to chemotherapy were compared with the 21 who did not. Preoperative chemotherapy was administered for 5.7 months, wherein 50 patients $(78 \%)$ received a single regimen, and $54(84 \%)$ received oxaliplatin. There were more patients with $<3$ metastases and maximum diameters $<5 \mathrm{~cm}$ in the non-NAC group. The median survival time was 86.0 and
\end{abstract}

Correspondence to: Professor Toshiya Kamiyama, Department of Gastroenterological Surgery I, Graduate School of Medicine, Hokkaido University, N-15, W-7, Kita-ku, Sapporo, Hokkaido 060-8638, Japan

E-mail: t-kamiya@med.hokudai.ac.jp

Abbreviations: FOLFOX, folinic-acid-fluorouracil-oxaliplatin; NAC, neoadjuvant chemotherapy; non-NAC, non-neoadjuvant chemotherapy; HR, hazard ratio; OR, odds ratio; OS, overall survival; PFS, progression-free survival; RECIST, Response Evaluation Criteria in Solid Tumors; RFS, relapse-free survival; SAR, survival after recurrence, CI, confidence interval; CRC, colorectal carcinoma; EGFR, epidermal growth factor receptor

Key words: colorectal carcinoma, liver metastasis, oncology, chemotherapy, survival, hepatectomy
71.6 months in the NAC and non-NAC groups, respectively $(\mathrm{P}=0.33)$. Subgroup analysis on the basis of tumor size and number showed no prognostic differences between the two groups. The median survival time was longer in responders than in non-responders ( 85 vs. 56 months; $\mathrm{P}=0.01$ ). However, the median relapse-free survival was equivalent in both groups (16.4 and 10.7 months). Preoperative chemotherapy did not prolong survival. Furthermore, it did not prevent recurrence, even in clinical responders. Therefore, it should not be routinely offered to patients with resectable liver metastasis before their hepatectomy.

\section{Introduction}

Colorectal carcinoma (CRC) is a common malignancy in both sexes and a freFquent cause of cancer-related death. Approximately $20 \%$ of patients with newly diagnosed CRC will have synchronous metastatic disease (1), and $15 \%$ will have resectable liver metastasis (2-4). Resection of metastases limited to the liver coupled with resection of the primary tumor is associated with significant improvement in survival $(5,6)$.

Chemotherapy after the hepatectomy may improve the survival of patients with resectable CRC liver metastasis (7). However, the optimal duration, timing, and regimen for this improvement have not been established. Furthermore, preoperative chemotherapy bridging to surgical intervention in primary unresectable CRC liver metastasis has been shown to be beneficial $(8,9)$. The response to preoperative chemotherapy is useful to predict the prognosis in initially unresectable and resectable disease (10). However, the prognostic benefit of chemotherapy before hepatectomy in patients with CRC and resectable or marginally resectable liver metastases remains unclear. It has been reported that the prognosis of patients with synchronous and metachronous CRC liver metastasis is different $(11,12)$. Therefore, we focused on CRC with synchronous liver metastasis and investigated whether preoperative chemotherapy improved the surgical curability in this patient population by assessing survival time and recurrence. 


\section{Patients and methods}

Patients. This retrospective study involved 106 patients treated at three Japanese hospitals. We investigated patients with $\mathrm{CRC}$ and resectable or marginally resectable synchronous metastases treated at Hokkaido University Hospital, Hokkaido Cancer Center, and Hokkaido Hospital, Japan Community Health Care Organization (all in Hokaido, Japan) between April 2006 and August 2017. Patients were excluded if they had any other distant metastases at the first treatment (surgery or prior chemotherapy). Simultaneous or metachronous resection of the primary lesion and liver metastasis; surgical approach (open or laparoscopic); and the duration, timing, and regimen of chemotherapy (including adjuvant therapy) were decided at the discretion of the attending surgeon and medical oncologist in each case. We retrospectively collected and analyzed information about all eligible patients from their medical charts.

Overall survival (OS) was defined as the interval between the day of the first treatment and the day of death from any cause or the last follow-up. We compared the OS of 64 patients who received neoadjuvant chemotherapy (NAC) with that of 42 patients who did not. To assess the prognostic course after surgery, we also compared OS, relapse-free survival (RFS), and survival after recurrence (SAR) between 43 patients who responded to preoperative chemotherapy (responders) and 21 who did not (non-responders).

Liver metastases were classified into three subgroups, H1, $\mathrm{H} 2$, and $\mathrm{H} 3$, according to their extent. $\mathrm{H} 1$ comprised patients with fewer than three liver metastases with a maximum diameter $<5 \mathrm{~cm}$, whereas $\mathrm{H} 3$ comprised those with more than four metastases with a maximum diameter $>5 \mathrm{~cm}$. The H2 subgroup comprised patients who were excluded from subgroups H1 and H3 (13). Clinical responses to the preoperative chemotherapy were evaluated on the basis of the revised Response Evaluation Criteria in Solid Tumors (RECIST) guidelines, version 1.1 (14).

The Ethics Committees of Hokkaido University Hospital and all participating hospitals approved this study as an exempt human subject research (no. 017-0399) and informed consent was obtained from all patients by the opt-out method, in accordance with the guidelines of the Japanese Ministry of Health, Labor and Welfare (Tokyo, Japan).

Statistical analysis. Summary statistics for continuous data are described as mean and 95\% confidence intervals (CI). All statistical tests were performed with an $\alpha$ level of 0.05 (two-sided). The Chi-square test and Student's t-test were performed for categorical and continuous data, respectively. Survival curves and median follow-up times were estimated by the Kaplan-Meier method, and the survival curves of each group were compared using log-rank tests. Survival was compared in the NAC group and the non-NAC group, and then prognostic comparison between responders and non-responders in the NAC group was conducted. In the latter comparison, the survival curves of the non-NAC group were used for reference. To confirm the consistency of the primary results, Cox's proportional hazards regression was also performed to estimate the hazard ratios (HRs) while adjusting for baseline covariants. Multivariate regression analysis was conducted with selected values according to the pretreatment condition (primary site, primary tumor differentiation, age, sex, primary tumor depth, lymph node metastasis, number and size of liver metastasis, and lymph and venous vessel invasion in the primary lesion) and surgical strategy (simultaneous resection and preoperative chemotherapy). All statistical analyses were performed using JMP Pro, version 13.0.0 (SAS Institute, Inc.).

\section{Results}

Patient characteristics. Patient characteristics are shown in Table I. There was no difference in the site, histological type, tumor depth, and lymph node metastasis of the primary lesion between patients in the NAC group and those in the non-NAC group. There were more patients with $\mathrm{H} 1$ liver metastases in the non-NAC group (74\%) than in the NAC group (34\%). In the NAC group, preoperative chemotherapy was administered for 5.7 months, during which 50 patients $(78 \%)$ received a single regimen and 54 patients $(84 \%)$ received oxaliplatin. After evaluating the clinical response to chemotherapy in the NAC group, complete response, partial response, stable disease, and progressive disease were observed in 1 (2\%), 42 (67\%), 7 (11\%), and $14(21 \%)$ patients, respectively. Simultaneous resection of the primary lesion and liver metastasis was performed in 4 patients $(6 \%)$ in the NAC group and $21(50 \%)$ patients in the non-NAC group $(\mathrm{P}=0.0001)$. There were no differences between the two groups in terms of the type of procedure, histological margins, and administration of adjuvant chemotherapy. The duration of adjuvant chemotherapy was longer in the NAC group than in the non-NAC group $(\mathrm{P}=0.02)$, and irinotecan and bevacizumab were more commonly used in the NAC group $(\mathrm{P}=0.002)$.

Overall survival. The median follow-up period was 41 months (2.5-141.2 months). There were 1 and 2 patients lost to follow-up (because they moved away) in the NAC and non-NAC groups, respectively. The median survival and 5-year OS rates in the NAC and non-NAC groups were 86.0 and 71.6 months and 75.1 and $54.3 \%$, respectively $(\mathrm{P}=0.33$; Fig. 1$)$.

Risk factors for poor prognosis. Univariate regression analysis identified lymph vessel invasion in the primary lesion $[\mathrm{P}=0.002$; odds ratio (OR), 4.62; 95\% CI, 1.61-19.4] and female sex $(\mathrm{P}=0.03$; OR, 2.25; 95\% CI, 1.06-4.91) as positively associated with poor prognosis, while NAC status was not associated with poor prognosis $(\mathrm{P}=0.79$; OR, 0.93; 95\% CI, 0.56-1.49).

Multivariate regression analysis showed that undifferentiated adenocarcinoma $(\mathrm{P}=0.02$; OR, 3.84; 95\% CI, 1.16-12.1), a primary tumor invasion to the serosa or adjacent structures ( $\mathrm{P}=0.01$; OR, 4.99; 95\% CI, 1.39-19.9), and simultaneous resection $(\mathrm{P}=0.009 ; \mathrm{OR}, 5.39 ; 95 \% \mathrm{CI}$, 1.50-20.3) were associated with a poor prognosis. Not receiving preoperative chemotherapy was not associated with a poor prognosis $(\mathrm{P}=0.28$; Table II $)$.

Analysis of $O S, R F S$, and SAR according to H subgroups. Since there were differences between the NAC and non-NAC groups with respect to liver metastasis (subgroup $\mathrm{H}$ ), we stratified the patients into two groups, $\mathrm{H} 1$ and $\mathrm{H} 2 / \mathrm{H} 3$, and analyzed the OS, 
Table I. Patient characteristics.

\begin{tabular}{|c|c|c|c|}
\hline Variables & Non-NAC $(n=42)$ & NAC $(n=64)$ & P-value \\
\hline Age (years) & $64.0(61.1-66.9)$ & $61.2(58.9-63.5)$ & 0.14 \\
\hline Sex & & & 0.63 \\
\hline Male & $19(45 \%)$ & $26(41 \%)$ & \\
\hline Female & $23(55 \%)$ & $38(59 \%)$ & \\
\hline Tumor location (primary tumor) & & & 0.74 \\
\hline Right & $11(26 \%)$ & $15(23 \%)$ & \\
\hline Left & $31(74 \%)$ & $49(77 \%)$ & \\
\hline Histology $\mathrm{y}^{\mathrm{a}}$ & & & 0.72 \\
\hline Differentiated adenocarcinoma & $6(14 \%)$ & $9(14 \%)$ & \\
\hline Other & $35(83 \%)$ & $53(84 \%)$ & \\
\hline $\begin{array}{l}\text { Tumor invasion to serosa or adjacent } \\
\text { structures (primary tumor) }{ }^{\mathrm{a}}\end{array}$ & & & 0.86 \\
\hline No & $34(81 \%)$ & $46(72 \%)$ & \\
\hline Yes & $8(19 \%)$ & $17(27 \%)$ & \\
\hline Lymph node metastasis ${ }^{\mathrm{a}}$ & & & 0.61 \\
\hline Negative & $4(10 \%)$ & $8(13 \%)$ & \\
\hline Positive & $34(81 \%)$ & $49(77 \%)$ & \\
\hline Liver metastasis (pretreatment) & & & 0.0003 \\
\hline H1 & $9(21 \%)$ & $22(34 \%)$ & \\
\hline $\mathrm{H} 2$ & $31(74 \%)$ & $30(47 \%)$ & \\
\hline $\mathrm{H} 3$ & $2(5 \%)$ & $12(19 \%)$ & \\
\hline Liver metastasis (solitary and $<5 \mathrm{~cm}$ ) & & & 0.01 \\
\hline Yes & $12(29 \%)$ & $6(9 \%)$ & \\
\hline No & $30(71 \%)$ & $58(91 \%)$ & \\
\hline Lymph vessel invasion (primary tumor) ${ }^{\mathrm{a}}$ & & & 0.42 \\
\hline Negative & $12(29 \%)$ & $23(36 \%)$ & \\
\hline Positive & $28(67 \%)$ & $38(59 \%)$ & \\
\hline Venous invasion (primary tumor) ${ }^{\mathrm{a}}$ & & & 0.71 \\
\hline Negative & $7(17 \%)$ & $9(14 \%)$ & \\
\hline Positive & $33(79 \%)$ & $52(81 \%)$ & \\
\hline Primary resection & & & 0.0001 \\
\hline Simultaneous & $21(50 \%)$ & $4(6 \%)$ & \\
\hline Metachronous & $21(50 \%)$ & $60(94 \%)$ & \\
\hline Clinical response ${ }^{\mathrm{b}}$ & & & - \\
\hline $\mathrm{CR}$ & - & $1(2 \%)$ & \\
\hline PR & - & $42(66 \%)$ & \\
\hline SD & - & $7(11 \%)$ & \\
\hline PD & - & $14(22 \%)$ & \\
\hline Procedure & & & 0.84 \\
\hline Partial & $25(60 \%)$ & $35(55 \%)$ & \\
\hline Segmentectomy & $9(21 \%)$ & $14(22 \%)$ & \\
\hline Lobectomy & $8(19 \%)$ & $15(23 \%)$ & \\
\hline With ablation & & & 0.34 \\
\hline Yes & $3(7 \%)$ & $2(3 \%)$ & \\
\hline No & $39(93 \%)$ & $62(97 \%)$ & \\
\hline Histological margin ${ }^{\mathrm{a}}$ (liver specimens) & & & 0.56 \\
\hline Negative & $33(79 \%)$ & $46(72 \%)$ & \\
\hline Positive & $7(17 \%)$ & $16(25 \%)$ & \\
\hline Adjuvant chemotherapy & & & 0.13 \\
\hline Yes & $25(60 \%)$ & $47(73 \%)$ & \\
\hline No & $17(40 \%)$ & $17(27 \%)$ & \\
\hline
\end{tabular}


Table I. Continued.

\begin{tabular}{lcc}
\hline Variables & Non-NAC $(\mathrm{n}=42)$ & NAC $(\mathrm{n}=64)$ \\
\hline Waiting period (months) & $0.9(-2.7-4.6)$ & $3.02(0.21-5.84)$ \\
Duration (months) & $7.54(5.89-9.19)$ & $5.11(3.93-6.29)$ \\
Oxaliplatin & $13(52 \%)$ & 0.50 \\
Yes & $12(48 \%)$ & $20(43 \%)$ \\
No & & $27(57 \%)$ \\
5-FU only & $13(52 \%)$ & 0.19 \\
Yes & $12(48 \%)$ & $17(36 \%)$ \\
No & & $30(64 \%)$ \\
Irinotecan & 0 & 0.002 \\
Yes & $25(100 \%)$ & $15(32 \%)$ \\
No & & $32(68 \%)$ \\
Bevacizumab & $1(4 \%)$ & 0.04 \\
Yes & $24(96 \%)$ & $11(23 \%)$ \\
No & & $36(77 \%)$ \\
Re-hepatectomy after recurrence & $11(44 \%)$ & 0.73 \\
Yes & $16(64 \%)$ & $19(43 \%)$ \\
No & & $25(57 \%)$ \\
\hline
\end{tabular}

NAC, neoadjuvant chemotherapy; CR, complete response; PR, partial response; SD, stable disease; PD, progressive disease; FU, fluorouracil; $\mathrm{H} 1$, patients with fewer than 3 liver metastases with a maximum diameter $<5 \mathrm{~cm}$; H3, patients with more than 4 metastases with a max diameter $>5 \mathrm{~cm} ; \mathrm{H} 2$, patients excluded from subgroups $\mathrm{H} 1$ and $\mathrm{H} 3 ;{ }^{\mathrm{a}}$ value includes some missing data; ${ }^{\mathrm{b}}$ not $100 \%$ because the data are rounded to integers.

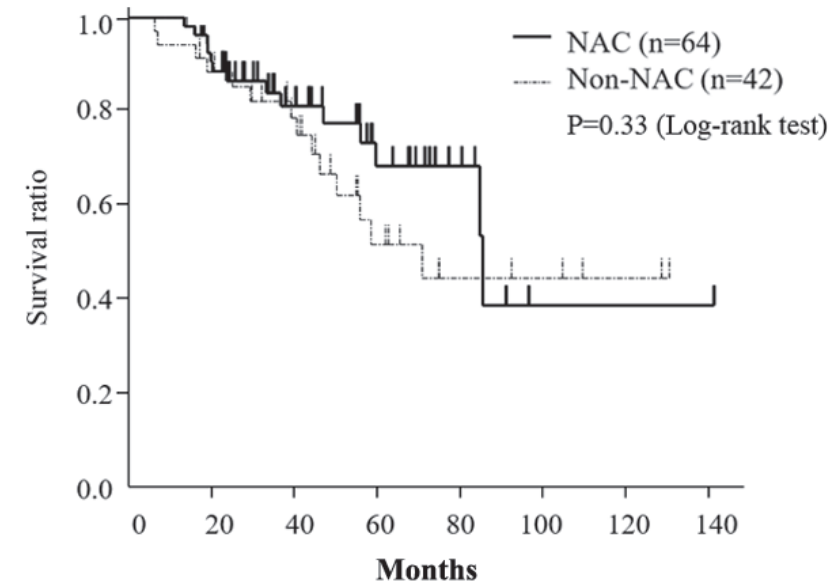

Figure 1. Association between preoperative chemotherapy status and overall survival Median survival and 5-year overall survival rates in the NAC and non-NAC groups were 86.0 and 71.6 months and 75.1 and $54.3 \%$, respectively. NAC, neoadjuvant chemotherapy.

RFS, and SAR in each. There were no survival differences between the NAC and non-NAC groups between the $\mathrm{H} 1$ $(\mathrm{P}=0.53)$ and $\mathrm{H} 2 / \mathrm{H} 3$ patients $(\mathrm{P}=0.16)$. Moreover, RFS and $\mathrm{SAR}$ in the NAC and non-NAC groups were not significantly different between the $\mathrm{H} 1(\mathrm{P}=0.36,0.45)$ and $\mathrm{H} 2 / \mathrm{H} 3$ patients ( $\mathrm{P}=0.26,0.24$; Fig. 2).

Prognosis of the patients who responded to preoperative chemotherapy. To assess the prognosis of responders $(n=43)$ and non-responders $(n=21)$, we compared their OS, RFS, and SAR.
Anti-epidermal growth factor receptor (EGFR) therapy was more commonly administered to the responders (25 patients, $58 \%$ ) than the non-responders (10 patients, 47\%). There was no difference in the characteristics of the primary lesion, type and timing of procedure, histological margins, and adjuvant chemotherapy between the two groups (Table III). The median OS was significantly longer in responders ( 85 months) than in non-responders (56 months). However, the median RFS in responders and non-responders was not significantly different at 16.4 and 10.7 months, respectively. In addition, the median SAR was significantly longer in responders (over 70 months) than in non-responders (24 months). OS, RFS, and SAR in the non-NAC group were 71.6, 17.2, and 44 months, respectively (Fig. 3). There was no difference in the characteristics of the first recurrence site and surgical intervention or chemotherapy administered after recurrence (Table III).

\section{Discussion}

We showed that preoperative chemotherapy in patients with CRC and synchronous liver metastasis did not prolong survival. Moreover, on the subgroup analysis of patients based on their response to chemotherapy, we notably demonstrated that even in responders it did not prolong RFS although it did prolong OS and SAR. This means that preoperative chemotherapy does not improve the curative potential of surgery but does improve the post-recurrence prognosis for responders. In other words, the response to the preoperative chemotherapy merely predicted the response to the chemotherapy after recurrence. Empirically, preoperative chemotherapy is often administered 
Table II. Risk factors for shorter survival.

\begin{tabular}{|c|c|c|c|}
\hline \multirow[b]{2}{*}{ Risk factor } & \multicolumn{3}{|c|}{ Multivariate analysis } \\
\hline & HR & $95 \% \mathrm{CI}$ & P-value \\
\hline Primary site & & & 0.84 \\
\hline Left & 1.00 & - & \\
\hline Right & 0.89 & $0.29-2.54$ & \\
\hline Differentiated adenocarcinoma & & & 0.02 \\
\hline Yes & 1.00 & - & \\
\hline No & 3.84 & $1.16-12.1$ & \\
\hline Age (years) & & & 0.28 \\
\hline$<50$ & 1.00 & - & \\
\hline$\geq 50$ & 2.30 & $0.54-16.3$ & \\
\hline Sex & & & 0.63 \\
\hline Male & 1.00 & - & \\
\hline Female & 1.29 & $0.44-3.82$ & \\
\hline Tumor invasion to serosa or adjacent structures (primary tumor) & & & 0.01 \\
\hline No & 1.00 & - & \\
\hline Yes & 4.99 & $1.39-19.9$ & \\
\hline Lymph node metastasis & & & 0.96 \\
\hline Negative & 1.00 & - & \\
\hline Positive & 1.03 & $0.27-5.11$ & \\
\hline Liver metastasis & & & 0.07 \\
\hline H1 & 1.00 & - & \\
\hline $\mathrm{H} 2$ & 1.02 & $0.32-3.25$ & \\
\hline H3 & 3.76 & $0.89-16.1$ & \\
\hline Liver metastasis (solitary and $<5 \mathrm{~cm}$ ) & & & 0.20 \\
\hline Yes & 1.00 & - & \\
\hline No & 2.82 & $0.58-21.0$ & \\
\hline Lymph vessel invasion (primary tumor) & & & 0.07 \\
\hline Negative & 1.00 & - & \\
\hline Positive & 3.11 & $0.89-14.8$ & \\
\hline Venous invasion (primary tumor) & & & 0.75 \\
\hline Negative & 1.00 & - & \\
\hline Positive & 1.25 & $0.33-6.28$ & \\
\hline Simultaneous resection & & & 0.009 \\
\hline No & 1.00 & - & \\
\hline Yes & 5.39 & $1.50-20.3$ & \\
\hline NAC & & & 0.28 \\
\hline No & 1.00 & - & \\
\hline Yes & 0.57 & $0.21-1.59$ & \\
\hline
\end{tabular}

HR, hazard ratio; CI, confidence interval; NAC, neoadjuvant chemotherapy; H1, patients with fewer than 3 liver metastases with a maximum diameter $<5 \mathrm{~cm} ; \mathrm{H} 3$, patients with more than 4 metastases with a maximum diameter $>5 \mathrm{~cm} ; \mathrm{H} 2$, patients excluded from subgroups $\mathrm{H} 1$ and $\mathrm{H} 3$.

to allow an observational period to determine whether new lesions will appear soon after the first treatment. However, on the basis of the findings of the current study, this approach is not logical because there were no differences in the time to relapse after the hepatectomy whether chemotherapy was administered before the hepatectomy or not. Therefore, surgery should be recommended for patients with CRC and synchronous liver metastasis when the attending surgeon determines the tumor to be resectable. Additionally, when we compared the poor prognostic factors using a Cox regression analysis in the NAC or non-NAC groups independently, the hepatic factor after neoadjuvant chemotherapy along with the $\mathrm{T}$ factor in the primary site were independent prognostic factors in the NAC group (Table SI), whereas being female, the absence of 
A

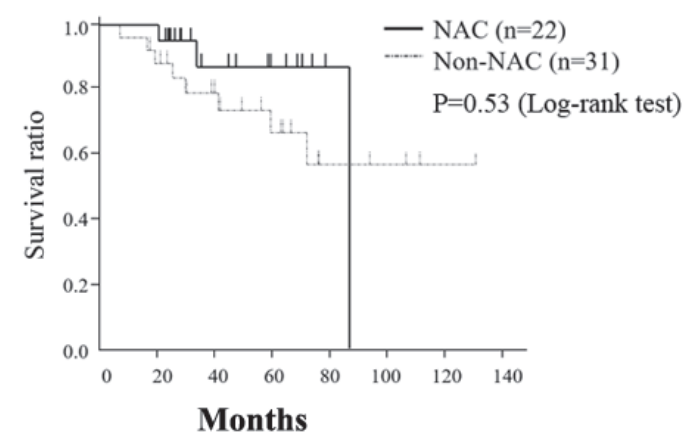

$\mathrm{C}$

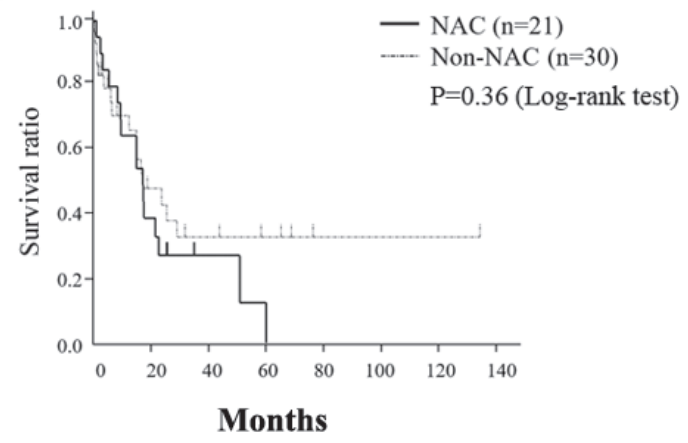

$\mathrm{E}$

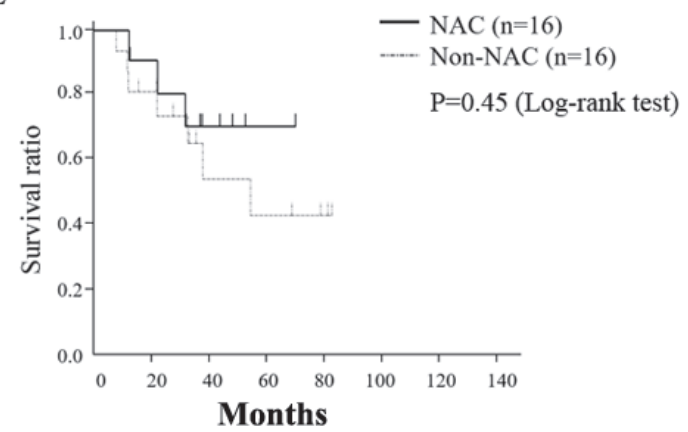

B

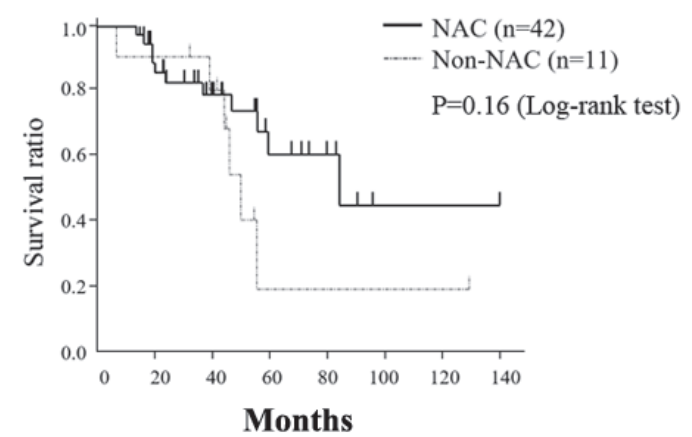

$\mathrm{D}$

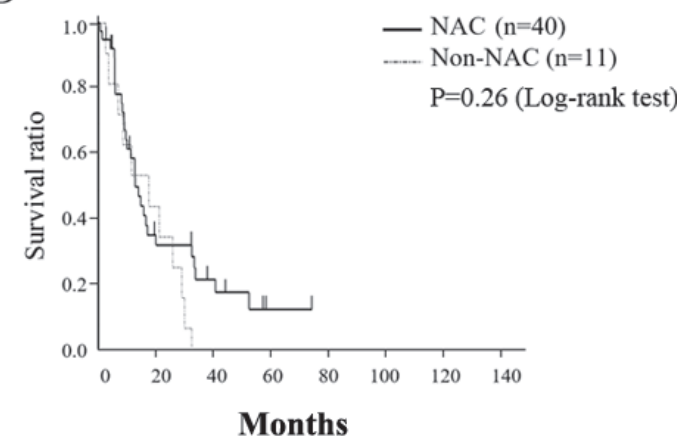

$\mathrm{F}$

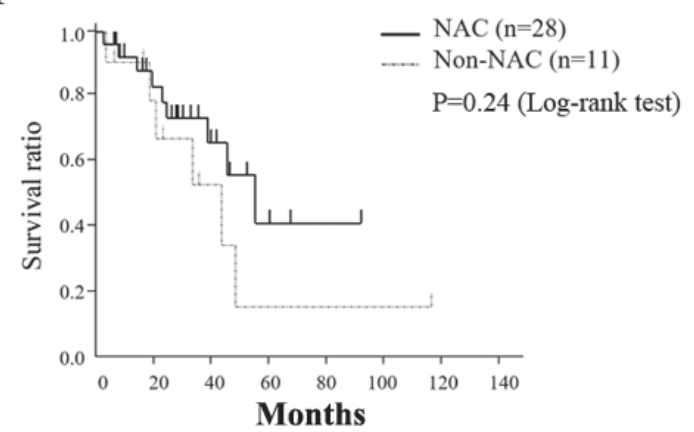

Figure 2. Association between preoperative chemotherapy status and overall, relapse-free and after recurrence survival (subgroup analysis). (A) OS in H1; (B) OS in H2, 3; (C) RFS in H1; (D) RFS in H2, 3; (E) SAR in H1; (F) SAR in H2 and H3. NAC, neoadjuvant chemotherapy; RFS, relapse-free survival; SAR, survival after recurrence; OS, overall survival; H1, patients with fewer than 3 liver metastases with a maximum diameter <5 cm; H3, patients with more than 4 metastases with a maximum diameter $>5 \mathrm{~cm} ; \mathrm{H} 2$, patients excluded from subgroups $\mathrm{H} 1$ and $\mathrm{H} 3$.

adjuvant chemotherapy, and the lymph vessel invasions in the primary site were independent factors in the non-NAC group (Table SII). It is significant that the $\mathrm{H}$ factor after neoadjuvant therapy was one of the independent prognostic factors in the NAC group because it reflected the response to chemotherapy. In fact, 21 and $4 \%$ of the cases had down- and up-stages of the $\mathrm{H}$ factor, respectively. In that mean, in more cases, NAC improved the resectability. In marginal cases, resectability differs depending on the attending surgeon (15), and NAC may improve the opportunity for safe resections. However, in the present study, NAC did not improve recurrent free survival even in the responders, although it improved the survival time by prolonging survival after recurrence. Therefore, waiting periods in considering recurrence after resection might not be needed in easily resectable cases. It is not beneficial to introduce watching and neoadjuvant chemotherapy in cases in which the hepatic metastasis can be safely resected. Therefore, we suggested that NAC should not be routinely offered to patients with resectable liver metastasis before hepatectomy.

The present's study findings are in accordance with those of the European Organisation for Research and Treatment of Cancer Intergroup trial 40983, a large, European randomized controlled trial in which preoperative folinic acid-fluorouracil-oxaliplatin (FOLFOX) therapy was not found to be beneficial $(16,17)$. However, it is possible that some biases may have detracted from the prognostic analyses in the present study. The patients in the NAC group had more advanced hepatic metastatic stages before the treatment, and there were more solitary tumors $\leq 5 \mathrm{~cm}$ in the patients in the non-NAC group. It has been reported that such patients who undergo metastasectomy have a better prognosis without the need for chemotherapy (18). More patients in the non-NAC group underwent simultaneous resection of the primary and metastatic tumors, possibly because of easier resectability. 
Table III. Differences in patient characteristics between responders and non-responders to chemotherapy.

\begin{tabular}{|c|c|c|c|}
\hline Patient characteristic & Non-responders $(n=21)$ & Responders $(n=43)$ & P-value \\
\hline Age (years) & $62.0(58.3-65.7)$ & $60.8(58.3-63.4)$ & 0.60 \\
\hline Sex & & & 0.18 \\
\hline Male & $11(52 \%)$ & $15(35 \%)$ & \\
\hline Female & $10(48 \%)$ & $28(65 \%)$ & \\
\hline Tumor location & & & 0.05 \\
\hline Right & $8(38 \%)$ & $7(16 \%)$ & \\
\hline Left & $13(62 \%)$ & $36(84 \%)$ & \\
\hline Histolog $y^{a}$ & & & 0.25 \\
\hline Differentiated & $5(24 \%)$ & $4(9 \%)$ & \\
\hline Other & $16(76 \%)$ & $37(86 \%)$ & \\
\hline Tumor invasion to serosa or adjacent structures (primary tumor) ${ }^{\mathrm{a}}$ & & & 0.12 \\
\hline No & $11(52 \%)$ & $34(79 \%)$ & \\
\hline Yes & $10(48 \%)$ & $7(16 \%)$ & \\
\hline Lymph node metastasis ${ }^{\mathrm{a}}$ & & & 0.90 \\
\hline Negative & $3(14 \%)$ & $5(12 \%)$ & \\
\hline Positive & $17(81 \%)$ & $32(74 \%)$ & \\
\hline Liver metastasis (pretreatment) & & & 0.22 \\
\hline H1 & $8(38 \%)$ & $14(33 \%)$ & \\
\hline $\mathrm{H} 2$ & $7(33 \%)$ & $23(53 \%)$ & \\
\hline H3 & $6(29 \%)$ & $6(14 \%)$ & \\
\hline Lymph vessel invasion (primary tumor) ${ }^{\mathrm{a}}$ & & & 0.47 \\
\hline Negative & $6(29 \%)$ & $17(40 \%)$ & \\
\hline Positive & $14(67 \%)$ & $24(56 \%)$ & \\
\hline Venous invasion (primary tumor) ${ }^{\mathrm{a}}$ & & & 0.53 \\
\hline Negative & $2(10 \%)$ & $7(16 \%)$ & \\
\hline Positive & $18(86 \%)$ & $34(79 \%)$ & \\
\hline Primary resection & & & 0.44 \\
\hline Simultaneous & $19(90 \%)$ & $41(95 \%)$ & \\
\hline Metachronous & $2(10 \%)$ & $2(5 \%)$ & \\
\hline Neoadjuvant period (months) & $5.35(3.44-7.25)$ & $5.03(3.97-6.10)$ & 0.77 \\
\hline Regimen number & & & 0.58 \\
\hline 1 & $14(67 \%)$ & $36(84 \%)$ & \\
\hline 2 & $6(29 \%)$ & $4(9 \%)$ & \\
\hline 3 & $1(5 \%)$ & $3(7 \%)$ & \\
\hline Oxaliplatin & & & 0.83 \\
\hline Yes & $18(86 \%)$ & $36(84 \%)$ & \\
\hline No & $3(14 \%)$ & $7(16 \%)$ & \\
\hline 5-FU only & & & 0.97 \\
\hline Yes & $2(10 \%)$ & $4(9 \%)$ & \\
\hline No & $19(90 \%)$ & $39(91 \%)$ & \\
\hline Irinotecan & & & 0.40 \\
\hline Yes & $8(38 \%)$ & $12(28 \%)$ & \\
\hline No & $13(62 \%)$ & $31(72 \%)$ & \\
\hline Bevacizumab & & & 0.42 \\
\hline Yes & $10(48 \%)$ & $25(58 \%)$ & \\
\hline No & $11(52 \%)$ & $18(42 \%)$ & \\
\hline Cetuximab/Panitumumab & & & 0.02 \\
\hline Yes & $3(14 \%)$ & $18(42 \%)$ & \\
\hline No & $18(86 \%)$ & $25(58 \%)$ & \\
\hline New lesion after NAC (extra hepatic) & $3(14 \%)$ & 0 & 0.01 \\
\hline
\end{tabular}


Table III. Continued.

\begin{tabular}{|c|c|c|c|}
\hline Patient characteristic & Non-responders $(\mathrm{n}=21)$ & Responders $(n=43)$ & P-value \\
\hline Procedure & & & 0.44 \\
\hline Partial resection & $9(43 \%)$ & $26(60 \%)$ & \\
\hline Segmentectomy & $5(24 \%)$ & $9(21 \%)$ & \\
\hline Lobectomy & $7(33 \%)$ & $8(19 \%)$ & \\
\hline With ablation & & & 0.59 \\
\hline Yes & $1(5 \%)$ & $1(2 \%)$ & \\
\hline No & $20(95 \%)$ & $42(98 \%)$ & \\
\hline Histological margina (liver specimens) & & & 0.05 \\
\hline Negative & $11(52 \%)$ & $35(81 \%)$ & \\
\hline Positive & $9(43 \%)$ & $7(16 \%)$ & \\
\hline Hepatic recurrence & & & 0.94 \\
\hline Yes & $11(73 \%)$ & $21(72 \%)$ & \\
\hline No & $4(27 \%)$ & $8(28 \%)$ & \\
\hline Pulmonary recurrence & & & 0.69 \\
\hline Yes & $5(33 \%)$ & $8(28 \%)$ & \\
\hline No & $10(67 \%)$ & $21(72 \%)$ & \\
\hline Peritoneal recurrence & & & 0.46 \\
\hline Yes & 0 & $1(3 \%)$ & \\
\hline No & $15(100 \%)$ & $28(97 \%)$ & \\
\hline Re-hepatectomy after recurrence & & & 0.34 \\
\hline Yes & $5(33 \%)$ & $14(48 \%)$ & \\
\hline No & $10(67 \%)$ & $15(52 \%)$ & \\
\hline Pulmonary resection after recurrence & & & 0.76 \\
\hline Yes & $2(13 \%)$ & $3(10 \%)$ & \\
\hline No & $13(87 \%)$ & $26(90 \%)$ & \\
\hline
\end{tabular}

FU, fluorouracil; NAC, neoadjuvant chemotherapy; H1, patients with fewer than 3 liver metastases with a maximum diameter $<5 \mathrm{~cm}$; $\mathrm{H} 3$, patients with more than 4 metastases with a maximum diameter $>5 \mathrm{~cm} ; \mathrm{H} 2$, patients excluded from subgroups $\mathrm{H} 1$ and $\mathrm{H} 3$. ${ }^{\mathrm{a}}$ Value includes some missing data.

Nevertheless, previous studies have shown no difference in recurrence and survival between patients undergoing simultaneous and metachronous liver resection $(19,20)$. In an attempt to adjust for these biases, we assessed the risk factors for a poor prognosis. Multivariate regression analysis of the pretreatment condition and surgical strategy also revealed that preoperative chemotherapy did not prolong OS. Moreover, there were no prognostic differences between the $\mathrm{H} 1$ and $\mathrm{H} 2 / \mathrm{H} 3$ subgroups of the NAC and non-NAC groups. Unfortunately, we lacked the efficient appropriate data about on the RAS and B-RAF mutations. However, regarding the K-RAS exon 2, we had the data on 17 cases in the non-NAC group and 55 cases in the NAC group. In these 72 cases, the overall survival between the K-RAS wild-type genes and mutations showed no differences (Fig. S1). The Cox regression also showed that both the NAC and K-RAS mutations were not prognostic factors regarding the overall survival (Table SIII).

Regarding the association between the clinical response and PFS, Yoshita et al reported a positive correlation between the clinical response to preoperative chemotherapy and prolonged PFS (21), in contrast to our report, using RECIST and computed tomography morphologic criteria $(22,23)$. In their report, the median PFS was 4.6 months longer in responders than in non-responders. However, almost all patients in both groups ultimately developed recurrence within 30 months (21). Thus, preoperative chemotherapy delayed recurrence slightly in responders but did not improve the recurrence rate. Therefore, we still recommend surgery as the initial treatment in patients with CRC and resectable liver metastasis. We additionally analyzed the prognostic impact of adjuvant and neoadjuvant usage of bevacizumab and cetuximab/panitumumab, respectively. None of the neoadjuvant or adjuvant usages of anti-tumoral medicines influenced PFS. Instead, T, N, and lymph vessel invasion in the primary site along with historically positive margins had poor prognosis in terms of recurrence (Table SIV). However, the number cases of each usage of the agent was limited. Therefore, further investigations with more cases are needed.

In addition to the small sample size and retrospective design, the greatest limitation of this study is that the preoperative chemotherapy regimens were not standardized, although the majority contained oxaliplatin. There is no established regimen 

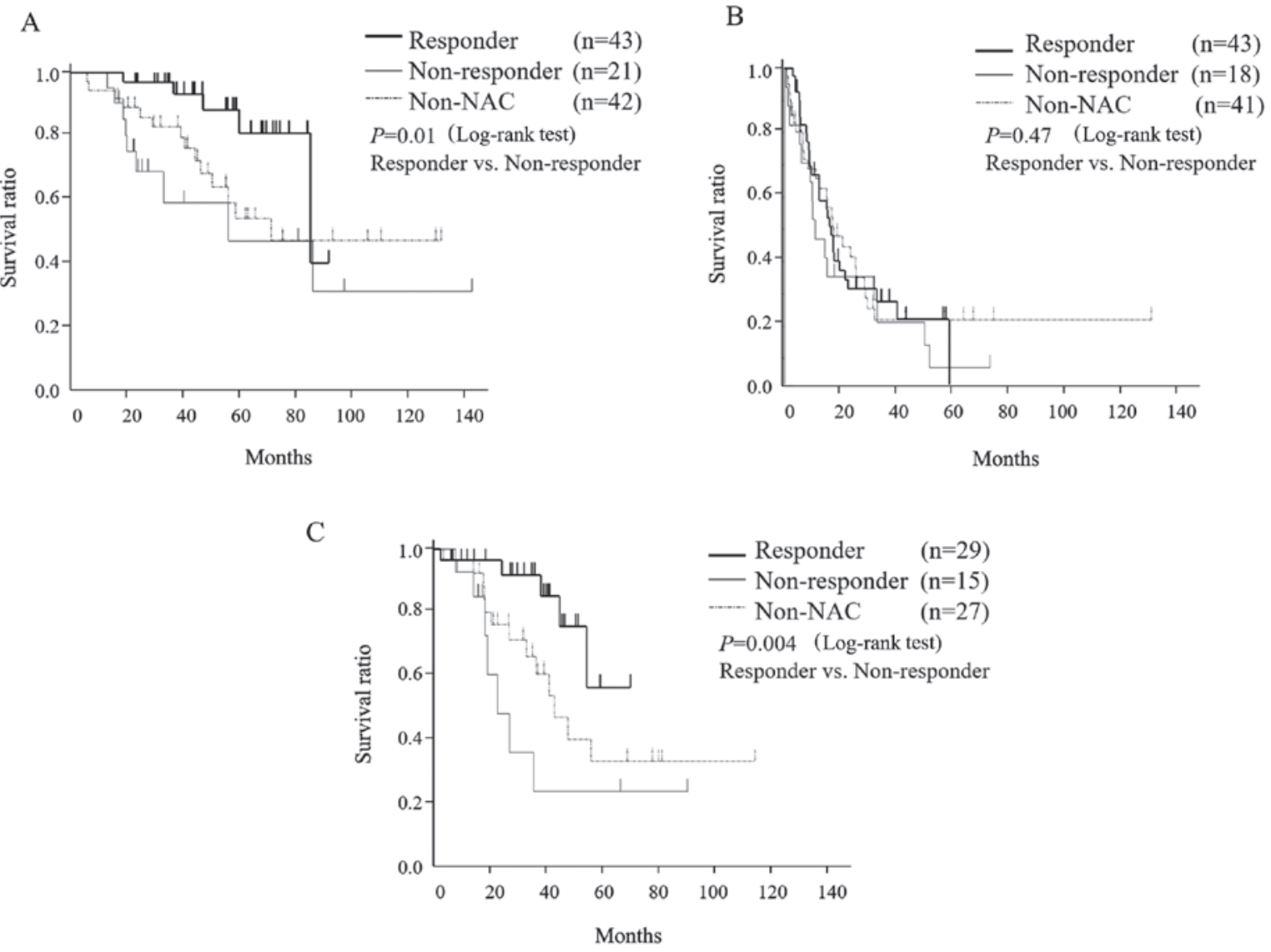

Figure 3. Association between response to preoperative chemotherapy and (A) OS, (B) RFS and (C) SAR. OS, overall survival; RFS, relapse-free survival; SAR, survival after recurrence.

in the adjuvant or neoadjuvant setting for resectable CRC liver metastasis $(7,12,18)$. However, for conversion therapy of unresectable metastasis, both oxaliplatin and irinotecan with anti-vascular endothelial growth factor receptor or anti-EGFR antibodies have been reported to be effective in decreasing the size or number of metastatic tumors $(8,9)$. If the aim is to improve tumor resectability of marginally resectable tumors, administering preoperative chemotherapy and selecting the regimen according to the concept of conversion therapy can be a rational approach. Tumor response reaches a plateau within eight weeks of chemotherapy $(9,24)$, and six cycles or more of FOLFOX increase postoperative morbidity due to sinusoidal injury (25). Therefore, four to six cycles of preoperative chemotherapy are suitable for downsizing marginally unresectable tumors to enable safe resection. Although this study provides significant and clinically relevant findings regarding the implications of preoperative chemotherapy, prospective studies with standardized patient characteristics and chemotherapy regimens are needed to validate our results.

In conclusion, we found that preoperative chemotherapy in patients with CRC and synchronous liver metastasis did not prolong survival or improve surgical curability. Preoperative chemotherapy is a useful predictor, as response to the chemotherapy before the surgery reflects the response to the chemotherapy after the recurrence. However, preoperative chemotherapy did not prevent recurrence, even in responders. Therefore, hepatectomy in patients with CRC and synchronous liver metastasis should be recommended if the tumor is determined to be resectable, and preoperative chemotherapy should not be routinely offered to patients with resectable liver metastasis before their hepatectomy.

\section{Acknowledgements}

The authors would like to thank Dr Futoshi Kawamata, Dr Hirofumi Kamachi, Dr Tatsuya Orimo, Dr Kenji Wakayama, Dr Shingo Shimada, Dr Akihisa Nagatsu, Dr Takanori Ohata, Dr Yosuke Ohno, Dr Susumu Shibasaki, Dr Hideki Kawamura (Department of Gastroenterological Surgery 1, Graduate School of Medicine, Hokkaido University), Dr Tomonori Hamada (Department of Gastroenterological Surgery, Hokkaido Cancer Center), and Dr Kazuaki Nakanishi (Department of Surgery, Hokkaido Hospital, Japan Community Healthcare Organization) for help with data collection and useful discussions.

\section{Funding}

No funding was received.

\section{Availability of data and materials}

All data generated or analyzed during this study are included in this published article. 


\section{Authors' contributions}

NI, TK, HY, SH, YM, TS, YT, KK, HI, TY and AT substantially contributed to the conception and design; acquisition, analysis, and interpretation of data; drafting of the article or revising it critically for important intellectual content. All authors read and approved the final manuscript.

\section{Ethics approval and consent to participate}

The Ethics Committees of Hokkaido University Hospital and all participating hospitals approved this study as an exempt human subject research (no. 017-0399) and informed consent was obtained from all patients by the opt-out method, in accordance with the guidelines of the Japanese Ministry of Health, Labor and Welfare (Tokyo, Japan).

\section{Patient consent for publication}

Not applicable.

\section{Competing interests}

The authors declare that they have no competing interests.

\section{References}

1. Cook AD, Single R and McCahill LE: Surgical resection of primary tumors in patients who present with stage IV colorectal cancer: An analysis of surveillance, epidemiology, and end results data, 1988 to 2000. Ann Surg Oncol 12: 637-645, 2005.

2. Nordlinger B, Van Cutsem E, Rougier $\mathrm{P}$, Köhne $\mathrm{CH}$, Ychou M, Sobrero A, Adam R, Arvidsson D, Carrato A, Georgoulias V, et al: Does chemotherapy prior to liver resection increase the potential for cure in patients with metastatic colorectal cancer? A report from the European Colorectal Metastases Treatment Group. Eur J Cancer 43: 2037-2045, 2007.

3. Van den Eynde M and Hendlisz A: Treatment of colorectal liver metastases: A review. Rev Recent Clin Trials 4: 56-62, 2009.

4. Poston GJ, Figueras J, Giuliante F, Nuzzo G, Sobrero AF, Gigot JF, Nordlinger B, Adam R, Gruenberger T, Choti MA, et al: Urgent need for a new staging system in advanced colorectal cancer. J Clin Oncol 26: 4828-4833, 2008

5. Abdalla EK, Vauthey JN, Ellis LM, Ellis V, Pollock R, Broglio KR, Hess K and Curley SA: Recurrence and outcomes following hepatic resection, radiof requency ablation, and combined resection/ablation for colorectal liver metastases. Ann Surg 239: 818-825; discussion 825-827, 2004.

6. Oba M, Hasegawa K, Shindoh J, Yamashita S, Sakamoto Y, Makuuchi M and Kokudo N: Survival benefit of repeat resection of successive recurrences after the initial hepatic resection for colorectal liver metastases. Surgery 159: 632-640, 2016.

7. Mitry E, Fields AL, Bleiberg H, Labianca R, Portier G, Tu D, Nitti D, Torri V, Elias D, O'Callaghan C, et al: Adjuvant chemotherapy after potentially curative resection of metastases from colorectal cancer: A pooled analysis of two randomized trials. J Clin Oncol 26: 4906-4911, 2008.

8. Bokemeyer C, Van Cutsem E, Rougier P, Ciardiello F, Heeger S, Schlichting M, Celik I and Köhne CH: Addition of cetuximab to chemotherapy as first-line treatment for KRAS wild-type metastatic colorectal cancer: Pooled analysis of the CRYSTAL and OPUS randomized clinical trials. Eur J Cancer 48: 1466-1475, 2012.

9. Folprecht G, Gruenberger T, Bechstein WO, Raab HR, Lordick F, Hartmann JT, Lang H, Frilling A, Stoehlmacher J, Weitz J, et al: Tumour response and secondary resectability of colorectal liver metastases following neoadjuvant chemotherapy with cetuximab: The CELIM randomised phase 2 trial. Lancet Oncol 11: 38-47, 2010.
10. Shin SJ, Ahn JB, Choi JS, Choi GH, Lee KY, Baik SH, Min BS, Hur H, Roh JK and Kim NK: Implications of clinical risk score to predict outcomes of liver-confined metastasis of colorectal cancer. Surg Oncol 21: e125-e130, 2012.

11. Lambert LA, Colacchio TA and Barth RJ Jr: Interval hepatic resection of colorectal metastases improves patient selection. Arch Surg 135: 473-479; discussion 479-480, 2000.

12. Nishioka Y, Moriyama J, Matoba S, Kuroyanagi H, Hashimoto M and Shindoh J: Prognostic impact of adjuvant chemotherapy after hepatic resection for synchronous and early metachronous colorectal liver metastases. Dig Surg 35: 187-195, 2018.

13. Japanese Society for Cancer of the Colon and Rectum: Japanese Classification of Colorectal Carcinoma. 9th edition. Kanehara \& Co. Ltd., Tokyo, p16, 2018.

14. Eisenhauer EA, Therasse P, Bogaerts J, Schwartz LH, Sargent D, Ford R, Dancey J, Arbuck S, Gwyther S, Mooney M, et al: New response evaluation criteria in solid tumours: Revised RECIST guideline (version 1.1). Eur J Cancer 45: 228-247, 2009.

15. Takatsuki M, Tokunaga S, Uchida S, Sakoda M, Shirabe K, Beppu T, Emi Y, Oki E, Ueno S, Eguchi S, et al: Evaluation of resectability after neoadjuvant chemotherapy for primary non-resectable colorectal liver metastases: A multicenter study. Eur J Surg Oncol 42: 184-189, 2016.

16. Nordlinger B, Sorbye H, Glimelius B, Poston GJ, Schlag PM, Rougier P, Bechstein WO, Primrose JN, Walpole ET, Finch-Jones M, et al: Perioperative chemotherapy with FOLFOX4 and surgery versus surgery alone for resectable liver metastases from colorectal cancer (EORTC Intergroup trial 40983): A randomised controlled trial. Lancet 371: 1007-1016, 2008.

17. Nordlinger B, Sorbye H, Glimelius B, Poston GJ, Schlag PM, Rougier P, Bechstein WO, Primrose JN, Walpole ET, Finch-Jones M, et al: Perioperative FOLFOX4 chemotherapy and surgery versus surgery alone for resectable liver metastases from colorectal cancer (EORTC 40983): Long-term results of a randomised, controlled, phase 3 trial. Lancet Oncol 14: 1208-1215, 2013.

18. Hasegawa K, Saiura A, Takayama T, Miyagawa S, Yamamoto J, Ijichi M, Teruya M, Yoshimi F, Kawasaki S, Koyama H, et al: Adjuvant oral uracil-tegafur with leucovorin for colorectal cancer liver metastases: A randomized controlled trial. PLoS One 11: e0162400, 2016

19. de Haas RJ, Adam R, Wicherts DA, Azoulay D, Bismuth H, Vibert E, Salloum C, Perdigao F, Benkabbou A and Castaing D: Comparison of simultaneous or delayed liver surgery for limited synchronous colorectal metastases. Br J Surg 97: 1279-1289, 2010.

20. Ali SM, Pawlik TM, Rodriguez-Bigas MA, Monson JRT, Chang GJ and Larson DW: Timing of surgical resection for curative colorectal cancer with liver metastasis. Ann Surg Oncol 25: 32-37, 2018.

21. Yoshita H, Hosokawa A, Ueda A, Ando T, Kajiura S, Kato H, Kawabe H, Tomizawa G, Horikawa N, Yabuhita K, et al: Predictive value of optimal morphologic response to first-line chemotherapy in patients with colorectal liver metastases. Digestion 89: 43-48, 2014.

22. Chun YS, Vauthey JN, Boonsirikamchai P, Maru DM, Kopetz S, Palavecino M, Curley SA, Abdalla EK, Kaur H, Charnsangavej C and Loyer EM: Association of computed tomography morphologic criteria with pathologic response and survival in patients treated with bevacizumab for colorectal liver metastases. JAMA 302: 2338-2344, 2009.

23. Shindoh J, Loyer EM, Kopetz S, Boonsirikamchai P, Maru DM, Chun YS, Zimmitti G, Curley SA, Charnsangavej C, Aloia TA and Vauthey JN: Optimal morphologic response to preoperative chemotherapy: An alternate outcome end point before resection of hepatic colorectal metastases. J Clin Oncol 30: 4566-4572, 2012.

24. Haller DG: Safety of oxaliplatin in the treatment of colorectal cancer. Oncology (Williston Park) 14: 15-20, 2000.

25. Nakano H, Oussoultzoglou E, Rosso E, Casnedi S, Chenard-Neu MP, Dufour P, Bachellier P and Jaeck D: Sinusoidal injury increases morbidity after major hepatectomy in patients with colorectal liver metastases receiving preoperative chemotherapy. Ann Surg 247: 118-124, 2008. 